\title{
Cinnamon Wood Biochar Characteristics and Application Rates Influence on Crop Growth and Properties of Problematic Soil in Southern Sri Lanka
}

\author{
D.J. Jayasanka, G.Y. Jayasinghe, S.A.D.S.S. Maheepala
}

\begin{abstract}
Biochar application has been provided various benefits to soil. This research was designed to assess the parameters between traditional biochar production system (TBS) and the innovative biochar production system (IS). The physical and chemical properties were assessed in two biochar materials that derived from traditional system (BCT) and the improved system (BCI). Also, soil properties changes and Ipomia aquatic plants growth were investigated after applying BCI at 0, 25, 50, 75 and $100 \%(v / v)$ input levels. Maximum heating temperature was increased up to $600{ }^{\circ} \mathrm{C}$ in IS since TBS reached to $500{ }^{\circ} \mathrm{C}$. Further, time consumption in IS was reduced by $20 \%$ than TBS for the same amount of feedstock. Ash content was increased by $2 \%$ in IS compared to TBS. Biochar C content was high compared with the original feedstock in both BCT and BCI. Organic C\% was increased by $55 \%$ and $75 \%$ in BCT and BCI, respectively. Particle-size was greater than $0.25 \mathrm{~mm}$ in $90 \%$ of total biochar of both samples. BCI showed significantly high organic carbon, porosity, WHC, $\mathrm{pH}$ and $\mathrm{EC}$ than BCT. There was a significant difference of $\mathrm{pH}, \mathrm{EC}$, porosity, $\mathrm{WHC}$, available $P$ and Exchangeable $K$ values among five treatments in the pot experiment. Mixing $75 \%$ biochar with acidic soil resulted neutral soil $\mathrm{pH}$ and recorded highest plant height and fresh weight compared with other combinations. Higher $C$ content in BCI may enhance the soil carbon sequestration and improve the crop growth. Furthermore, farmers can be adapted to this system which helps to enhance the properties of acidic soil in their farmlands while opening the possibility of using Cinnamon wood as biochar material.
\end{abstract}

Keywords: acidic soil, innovative biochar production system, pyrolysis, traditional biochar production system, biochar amendment

\section{INTRODUCTION}

Soil sustainability and carbon sequestration emerged as important concerns in the new millennium due to the effect of global climate change [1]. Soil organic matter level is one of a key factor which influence on soil sustainability and carbon sequestration [2]. Therefore, developing strategies for

Revised Manuscript Received on January 2, 2020.

* Correspondence Author

*10.J. Jayasanka, Department of Biosystems Technology, Faculty of Technology, University of Sri Jayewardenepura, Sri Lanka Email: dkjjayasanka@sjp.ac.lk

${ }^{2}$ G.Y. Jayasinghe, Department of Agricultural Engineering, Faculty of Agriculture, University of Ruhuna, Sri Lanka. Email: jayasinghe@ageng.ruh.ac.lk

S.A.D.S.S. Maheepala Department of Agricultural and Plantation Engineering, Faculty of Engineering and Technology, Open University of Sri Lanka, Sri Lanka. Email: ssharu_92@yahoo.com increasing carbon sequestration in agricultural lands is

necessary to enhance the soil sustainability. Biochar is producing through the pyrolysis of organic waste. Biochar is consisting of chemically and biologically stable organic C [3]. Biomass sources such as plant residues, green manure, timber and agricultural waste can be used to produce biochar [4]. Soil physical, chemical and biological properties can be improved by the biochar application. In addition, biochar application decreasing the greenhouse gas emission though the carbon sequestration [5]. However, traditional biochar production system consists of several drawbacks such as emission of GHG during the pyrolysis process [6]. In the other hand, Cinnamon sticks (bark less woody material) use as firewood ever since in Sri Lanka. In addition, Nilwala farmers experienced severe crop failures annually due to low $\mathrm{pH}$ of their farmlands [7]. Hence, present research study attempted to design the biochar production process, to assess the physicochemical properties of Cinnamon wood biochar and to assess the possibility of using Cinnamon wood biochar as a soil amendment in problematic soils in southern Sri Lanka.

\section{METHODOLOGY}

\section{A. Biochar production}

Cinnamon (Cinnamomum zeylanicum) sticks (bark less) was used as feed stock. First, feed stock was cut into pieces of $30 \mathrm{~cm}$ using a knife. Then feed stock materials were air dried for $48 \mathrm{hrs}$. Consequently, $10 \mathrm{~kg}$ of cinnamon sticks were pyrolysed using traditional drum kiln and prototype kiln. Time consumption for pyrolysis, biochar yield percentage, ash content and maximum heating temperature were measured. The biochar materials produced from traditional method and improved method was referred as BCT and BCI respectively.

\section{B. Determination of physicochemical properties of Cinnamon wood biochar}

The $\mathrm{pH}$ of biochar and soil was measured using a $\mathrm{pH}$ meter [8]. The EC of biochar and soil was measured in using an EC meter [9]. Kjeldahl Nitrogen content in biochar was determined using Micro Kjeldahl Method. Total organic carbon content in biochar was measured by a method which was used by Walkley and Black [10]. Available P content in biochar and soil 
was measured using the Morgan's solution extraction method [11].

Exchangeable K content in biochar and soil was measured by using the ammonium acetate extraction method [12]. The pycnometer method was used [13] to determine the particle density of soil and biochar. The bulk densities of biochar and soil samples were measured by using a method which was described by Culley [14].

\section{Determine the influence of biochar application rates on soil quality and crop growth}

Different BCI contents were evaluated by growing Kangkun (Ipomia aquatic) in pots. Five treatments with different biochar and soil combinations (v/v): 0, 25, 50, 75 and 100 were tested. Physicochemical properties of samples were analyzed. The pot experiment was conducted using Completely Randomize Design consist three replicates. Data were analyzed using SAS. ANOVA tests were performed, and means were compared by Duncan's test at $\mathrm{P}<0.05$.

\section{RESULTS AND DISCUSSION}

\section{A. Characteristics of biochar}

Properties of biochar, yield and elemental composition are summarized in Table 1. Time consumption for pyrolysis the feedstock was decreased by $20 \%$ in improved system (IS) compared to the traditional barrel system (TBS). Maximum heating temperature was increased by $20 \%$ in the IS compared to the TBS. In general, biochar yield decreases when heating temperatures were increased. In this study, $\mathrm{BCI}$ yield was decreased by $2 \%$ compared to BCT. On the other hand, Ash content in IS was increased by $2 \%$ compared to TBS. As expected, $\mathrm{C}$ content in both BCT and BCI were higher than original feedstock. Organic $\mathrm{C} \%$ was increased by $55 \%$ in $\mathrm{BCT}$ and $75 \%$ in BCI compared to the original feedstock.

Herath et al., 2013 [15] also observed increased organic carbon content in biochar when pyrolysis temperature was increased. Bulk density of BCI was lower than BCT. Consequently, true density was high in BCI compared to $\mathrm{BCT}$. This negative relationship resulted high porosity and water holding capacity (WHC) in BCI compared to BCT. In general, an increase in solid density is accompanied by a decrease in bulk densities due to porosity develops during pyrolysis [16].

As summarized in table 1, $\mathrm{pH}$ and $\mathrm{EC}$ values of $\mathrm{BCI}$ were significantly $(\mathrm{P}<0.05)$ higher than $\mathrm{BCT}$. The results are similar to the work by Li et al., 2013 [17] who reported that comparatively lower $\mathrm{pH}$ and $\mathrm{EC}$ in rice straw biochar which produced below $400^{\circ} \mathrm{C}$ compared to rice straw biochar produced at $600{ }^{\circ} \mathrm{C} . \mathrm{pH}$ and $\mathrm{EC}$ of both $\mathrm{BCT}$ and BCI are higher than the typical $\mathrm{pH}$ and $\mathrm{EC}$ values of Maize Stover biochar, Coconut shell biochar, Groundnut shell biochar and Coir waste biochar. There was no significant difference $(\mathrm{P}>$ 0.05 ) between N, P and K levels of two biochar. Here, our results suggest that IS can be produced biochar more efficiently than TBS. To this end, results of our study revealed that $\mathrm{BCI}$ can be more effectively enhance the soil $\mathrm{C}$ sequestration, soil physical properties and $\mathrm{pH}$ than BCT.

Table 1. Pyrolysis yield and biochar characteristics

\begin{tabular}{|c|c|c|}
\hline Characteristics & BCT & $\mathrm{BCI}$ \\
\hline Time consumed (minutes) $)^{*}$ & 100 & 80 \\
\hline Marimum Heating temperature $(\mathrm{C})^{*}$ & 300 & 600 \\
\hline Biochar yield (G6) & 30 & 28 \\
\hline $\mathrm{OC}_{6}+$ & 62 & 70 \\
\hline Ash Content Hot $^{\circ}$ & 9 & 11 \\
\hline Bulk density $\left(\mathrm{g} \mathrm{cm}^{2}\right)^{t}$ & 0.23 & 0.2 \\
\hline True density $\left(\mathrm{g} \mathrm{cm}^{-1}\right)^{*}$ & 0.9 & 1.1 \\
\hline Porosity \% $^{*}$ & 74 & 80 \\
\hline WHC $y^{+}$ & 70 & 78 \\
\hline $\mathrm{pH}^{*}$ & 10.5 & 11.1 \\
\hline $\mathrm{EC}\left(\mathrm{mS} \mathrm{m}^{\mathrm{d}}\right)^{4}$ & 10.9 & 12.7 \\
\hline N4 & 0.154 & 0.164 \\
\hline$P \%$ & 0.35 & 0.37 \\
\hline $\mathrm{K} \%$ & 0.69 & 0.7 \\
\hline
\end{tabular}

* : Parameters are significant $(\mathrm{P}<0.05)$ between BCT and BCI

\section{B. Properties of different Treatments}

In this study, biochar amendment was significantly influenced on soil properties of treatments. There were significant differences $(\mathrm{P}<0.05)$ between porosity and WHC of treatments. Porosity and WHC of treatments were increased when increasing the biochar input level (Figure 1a). Thereby, the highest porosity and WHC was observed in T5. These results are similar to the work by Verheijen et al. [18] who observed increased WHC due to biochar application. Furthermore, $\mathrm{pH}$ and EC values of treatments were significantly different $(\mathrm{P}<0.05)$ from each other (Figure 1b). The $\mathrm{pH}$ and $\mathrm{EC}$ of treatments were increased with increase the biochar input level. The highest $\mathrm{pH}$ and $\mathrm{EC}$ was observed in T5. It was 6.5 and 1.5 -fold of increment than control.

However, $\mathrm{pH}$ of the $\mathrm{T} 4$ was neutral and here it is evident that mixing $75 \%$ of $\mathrm{BCI}$ enhanced the soil $\mathrm{pH}$ by 3.7 units compared with control. These findings are in agreement with Van Zwieten et al., 2010 [19] who demonstrated increase in soil $\mathrm{pH}$ from acidic to neutral with the application of paper mill biochar in a ferrosol: resulting in a concomitant reduction in exchangeable Al. Similar effects were observed in weathered tropical soils in Indonesia [20]. Study results suggest that application of BCI can be a viable strategy to enhance the $\mathrm{pH}$ of acidic soils while improve other soil properties such as porosity, WHC and EC which may generate positive impacts on crop growth. 


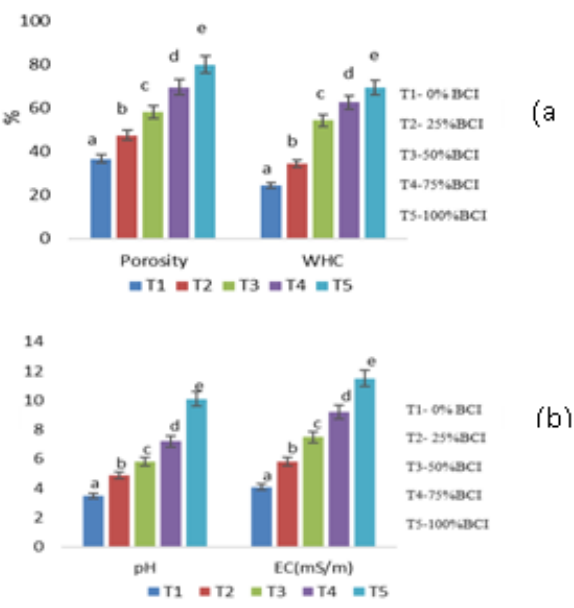

Figure 1. (a) Porosity and WHC of different treatments, (b) pH and EC values of different treatments

There was no significant difference $(\mathrm{p}>0.05)$ of the $\mathrm{N}$ content among all five treatments. In this study, nitrogen content of the initial soil was higher than the nitrogen content of biochar. Therefore, nitrogen content of the treatments which amended with different amount of biochar was lower than the control (zero amendment). Here, our results are similar with results reported by Carter et al., 2013 [21], who observed lower $\mathrm{N}$ content in rice husk biochar amended treatments compared with soil only control. However, there were significant differences $(\mathrm{P}<0.05)$ of $\mathrm{P}$ and $\mathrm{K}$ levels among treatments (Figure 2). The available $\mathrm{P}$ and exchangeable $\mathrm{K}$ contents of treatments were increased when increasing biochar input level. Furthermore, the highest $\mathrm{P}$ and $\mathrm{K}$ values observed in T5 and it was 2-fold and 3 -fold of increments compared to the control. The available $\mathrm{P}$ and exchangeable $\mathrm{K}$ contents of $\mathrm{BCI}$ were higher than the initial soil. Therefore, BCI amendments increased the soil P and $\mathrm{K}$ levels of other treatments than control. These results are similar to the work by Carter et al., 2013 [21], who observed increased soil $\mathrm{P}$ and $\mathrm{K}$ following the application of rice husk biochar in their pot experiment. The results of our study revealed that application of BCI to soil can be a viable strategy to maintain the soil sustainability in the agricultural lands via enhances the soil $\mathrm{P}$ and $\mathrm{K}$ levels. However, our results suggest that co-application of BCI with another organic amendment may be an effective strategy for compensating the limitations such as low $\mathrm{N}$ content of applying BCI alone.

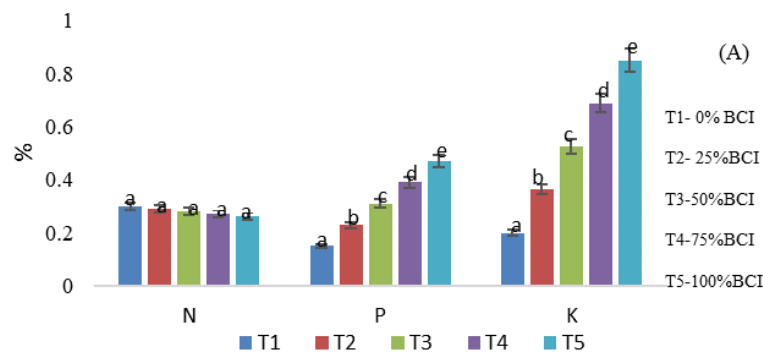

Figure 2. N, P, K levels of different treatments

\section{Influence of biochar application rates on crop growth}

In this research, T4 resulted the highest plant fresh weight while T3 showed the second highest plant fresh weight. In addition, T5 resulted the lowest plant fresh weight. As illustrated in Figure 3, 75, 50 and $25 \%$ biochar mixing to the soil significantly $(\mathrm{P}<0.05)$ increased the plant fresh weight of the Ipomia aquatic by 52, 30 and $18 \%$ respectively compared to the control. However, T5 (100\% BCI) significantly decreased $(\mathrm{P}<0.05)$ the plant fresh weight by $17 \%$ compared to control This trend was almost same for the plant height between treatments. Here, mixing 75, 50 and 25 $\%$ biochar with the soil significantly $(\mathrm{P}<0.05)$ increased the plant height of the Ipomia aquatic by 68, 56 and $25 \%$ respectively compared to the control. In this study, presence of BCI in soil directly enhanced the soil $\mathrm{pH}, \mathrm{EC}$, physical characteristics, water retention capacity and aggregation. These effects may facilitate to enhance the nutrient uptake by plants. However, application of wood biochar in higher rates could sometimes negatively affect plant growth. A decrease in crop growth due to high $\mathrm{C}: \mathrm{N}$ ratio in biochar [22], or to the increased soil $\mathrm{pH}[23]$.

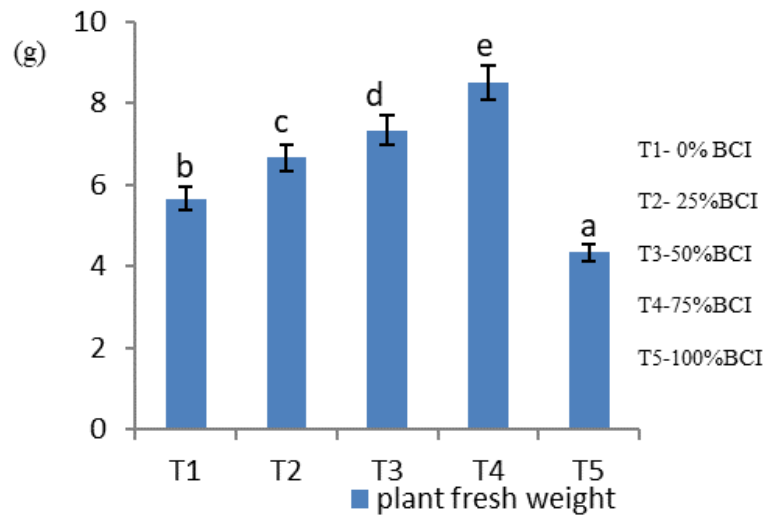

Figure 3. Effect of different treatment on crop growth

\section{CONCLUSION}

It can be concluded that the secondary burning system; Which was incorporated in the improved system was increased the temperature up to $600^{\circ} \mathrm{C}$ and reduced the time consumption by $20 \%$. This can be reduced the carbon monoxide $(\mathrm{CO})$, nitrous oxide $\left(\mathrm{N}_{2} \mathrm{O}\right)$ and methane $\left(\mathrm{CH}_{4}\right)$ emissions during the pyrolysis process and help to mitigate the global warming potential. Both BCT and BCI showed higher organic $\mathrm{C}$ content compared with the initial feedstock. Therefore, both biochar applications may increase the soil carbon sequestration. BCI showed higher $\mathrm{C}, \mathrm{pH}, \mathrm{EC}$ and WHC than in BCT. Thereby, BCI can be efficiently contributed to soil carbon sequestration and soil quality improvements in problematic soils in southern Sri Lanka. It can be concluded that BCI mixing with acidic soil until $75 \%$ $(\mathrm{v} / \mathrm{v})$ can be increased the yield of vegetable leaf plant (Ipomoea aquatiac). However, field trials need to carry out as further study. Farmers in the Nilwala river basin can be adapted to this system which helps to enhance the properties of acidic soil in their farmlands while opening the possibility of using Cinnamon wood as biochar material. 


\section{REFERENCES}

1. Adviento-Borbe, M. A. A., M. L. Haddix, D. L. Binder, D. T. Walters, and A. Dobermann. "Soil greenhouse gas fluxes and global warming potential in four high-yielding maize systems." Global Change Biology 13, no. 9 (2007), 1972-1988.

2. Carter, Martin R. "Soil quality for sustainable land management." Agronomy journal 94, no. 1 (2002), 38-47.

3. Lehmann, Johannes, Samuel Abiven, Markus Kleber, Genxing Pan, Bhupinder Pal Singh, Saran P. Sohi, and Andrew R. Zimmerman. "Persistence of biochar in soil." In Biochar for environmental management2015, 267-314

4. Woolf, Dominic, James E. Amonette, F. Alayne Street-Perrott, Johannes Lehmann, and Stephen Joseph. "Sustainable biochar to mitigate globa climate change." Nature communications 1 (2010), 56.

5. Zhao, X., J. W. Wang, H. J. Xu, C. J. Zhou, S. Q. Wang, and G. X. Xing. "Effects of crop-straw biochar on crop growth and soil fertility over a wheat-millet rotation in soils of $\mathrm{C}$ hina." Soil use and management 30, no. 3 (2014), 311-319.

6. Sohi, Saran, Elisa Lopez-Capel, Evelyn Krull, and Roland Bol. "Biochar, climate change and soil: A review to guide future research." CSIRO Land and Water Science Report 5, no. 09 (2009), 17-31.

7. Chandrasiri, P. A. N., and R. Pathirana. "Use of improved tolerant cultivars to increase rice production on acid histosols of southern $\mathrm{Sr}$ Lanka." In Plant-Soil Interactions at Low pH: Principles and Management, Springer, Dordrecht, (1995), 407-411.

8. Hendershot, W. H., H. Lalande, and M. Duquette. "Soil reaction and exchangeable acidity." Soil sampling and methods of analysis 2 (1993).

9. Bower, C. A., and L. V. Wilcox. "Soluble Salts 1." Methods of soil analysis. Part 2. Chemical and microbiological properties methodsofsoilanb (1965), 933-951.

10. Walkley, Aldous, and I. Armstrong Black. "An examination of the Degtjareff method for determining soil organic matter, and a proposed modification of the chromic acid titration method." Soil science 37, no. 1 (1934), 29-38

11. Byrne, Christopher E., and Dennis C. Nagle. "Carbonized wood monoliths - characterization." Carbon 35, no. 2 (1997), 267-273.

12. Thomas, G. W. "Exchangeable cations method of soil analysis." Part II Agronomy Monograph 9 (1982), 159-165.

13. Klute, A. "Methods of soil analysis: physical and mineralogical properties. Part I, ASA-SSSA." (1986), 377-382

14. Culley, J. L. B. "Density and compressibility in Soil sampling and methods of analysis (ed. Carter, MR)", (1993), 529-549.

15. Herath, H. M. S. K., Marta Camps-Arbestain, and Mike Hedley. "Effect of biochar on soil physical properties in two contrasting soils: an Alfisol and an Andisol." Geoderma 209 (2013), 188-197.

16. Guo, Jia, and Aik Chong Lua. "Characterization of chars pyrolyzed from oil palm stones for the preparation of activated carbons." Journal of Analytical and Applied Pyrolysis 46, no. 2 (1998), 113-125.

17. Li, Xiaoming, Qirong Shen, Dongqing Zhang, Xinlan Mei, Wei Ran, Yangchun $\mathrm{Xu}$, and Guanghui Yu. "Functional groups determine biochar properties ( $\mathrm{pH}$ and EC) as studied by two-dimensional 13C NMR correlation spectroscopy", PLoS One 8, no. 6 (2013),

18. Verheijen, F., S. Jeffery, A. C. Bastos, M. Van der Velde, and I. Diafas. "Biochar application to soils." A critical scientific review of effects on soil properties, processes, and functions, EUR 24099 (2010), 162.

19. Zimmerman, Andrew R. "Abiotic and microbial oxidation of laboratory-produced black carbon (biochar)." Environmental science \& technology 44, no. 4 (2010), 1295-1301.

20. Yamato, Masahide, Yasuyuki Okimori, Irhas Fredy Wibowo, Saifuddin Anshori, and Makoto Ogawa. "Effects of the application of charred bark of Acacia mangium on the yield of maize, cowpea and peanut, and soil chemical properties in South Sumatra, Indonesia." Soil science and plant nutrition 52, no. 4 (2006), 489-495.

21. Carter, Sarah, Simon Shackley, Saran Sohi, Tan Boun Suy, and Stephan Haefele. "The impact of biochar application on soil properties and plant growth of pot grown lettuce (Lactuca sativa) and cabbage (Brassica chinensis)." Agronomy 3, no. 2 (2013), 404-418.

22. Lehmann, Johannes, Jose Pereira da Silva, Christoph Steiner, Thomas Nehls, Wolfgang Zech, and Bruno Glaser. "Nutrient availability and leaching in an archaeological Anthrosol and a Ferralsol of the Central Amazon basin: fertilizer, manure and charcoal amendments." Plant and soil 249, no. 2 (2003), 343-357.

23. Tryon, Earl Haven. "Effect of charcoal on certain physical, chemical, and biological properties of forest soils." Ecological Monographs 18, no. 1 (1948), 81-115.

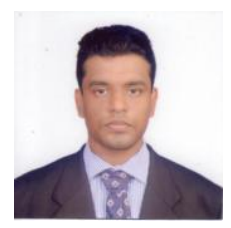

\section{AUTHORS PROFILE}

D.J. Jayasanka, Department of Biosystems Technology, Faculty of Technology, University of Sri Jayewardenepura, Sri Lanka. Dr. Dikkumburage Jasintha Jayasanka obtained his Ph.D from Tokyo University of Agriculture and Technology in the year 2018. He currently serving as a senior lecturer attached to Department of Biosystems Technology, University of Sri Jayewardenepura. He has been involved in many research and scientific publications.

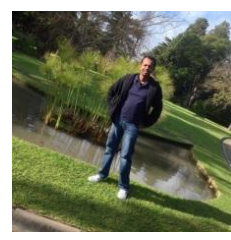

G.Y Jayasinghe, Department of Agricultural Engineering, Faculty of Agriculture, University of Ruhuna, Sri Lanka. Prof. G.Y Jayasinghe is currently serving as a professor attached to Department of Agricultural Engineering, University of Ruhuna. He has been involved in many research and scientific publications.



Ms. Shehani Sharadha Maheepala is a BSc in Green Technology Graduate from Faculty of Agriculture, University of Ruhuna and she is currently serving as a temporary lecturer to the Faculty of Engineering Technology, Open University of Sri Lanka. She has been involved in many research and scientific publications. 